\title{
Digital Maturity: Definition and Model
}

\author{
Aslanova I.V. ${ }^{1,2, *}$ Kulichkina A.I. ${ }^{1}$ \\ ${ }^{1}$ Faculty of Business, Novosibirsk State Technical University, Novosibirsk, 630087, Russia \\ ${ }^{2}$ Faculty of Business, Novosibirsk State Technical University, Novosibirsk, 630087, Russia \\ ${ }^{*}$ Corresponding author. Email: irina.aslanova@mail.ru
}

\begin{abstract}
Digital maturity is a phenomenon that has emerged along with the digital economy and Industry 4.0. Till now there is no common definition and understating of this process, so this research topic has plenty of room to study and explore. This article contains the definition of digital maturity based on the analysis of existing definitions, as well as overview and analysis of digital maturity models. The new model of digital maturity is as well represented, alongside with the first results received from applying it to clothing factory and oil and gas equipment manufacturing organization. Recommendations for these two companies are given based on results, recommendations were developed to help companies achieve a higher level of digital maturity and improve their performance, help them to achieve their operational goals, etc.
\end{abstract}

Keywords: digital maturity, digitalization, maturity model, digital transformation

\section{INTRODUCTION}

Digital transformation is a topical process that becomes a topic of discussion in the scientific community. Digital transformation, as a rule, means the application and use of modern technologies in the organization's business processes to achieve its goals and increase efficiency. Along with digital transformation, digital maturity is gaining more and more popularity. There is no single definition of digital maturity in the scientific field; table 1 presents the definitions of different authors.

Table 1 The definition of digital maturity by different authors

\begin{tabular}{|c|c|c|}
\hline № & Definition & Author and source \\
\hline 1 & $\begin{array}{l}\text { Digital maturity is about integrating your organization's } \\
\text { operations and human capital in digital processes and } \\
\text { vice versa. }\end{array}$ & $\begin{array}{l}\text { WalkMe pioneered the Digital Adoption Platform (DAP) } \\
\text { for organizations to utilize the full potential of their digital } \\
\text { assets. }\end{array}$ \\
\hline 2 & 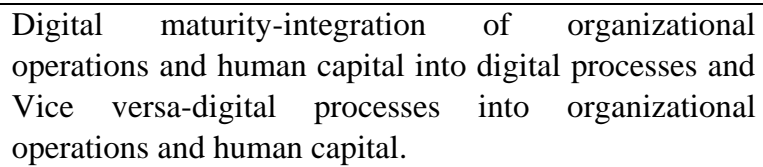 & $\begin{array}{l}\text { George Westerman, Didier Bonnet, and Andrew McAfee } \\
\text { "The Nine Elements of Digital Transformation" MIT } \\
\text { Sloan Management Review January 07, } 2014\end{array}$ \\
\hline 3 & $\begin{array}{l}\text { Digital maturity - how organizations systematically } \\
\text { prepare to adapt consistently to ongoing digital change. } \\
\text { Digital maturity draws on a psychological definition of } \\
\text { "maturity" that is based upon a learned ability to } \\
\text { respond to the environment in an appropriate manner }\end{array}$ & $\begin{array}{l}\text { G.C. Kane, "Digital Maturity, Not Digital } \\
\text { Transformation," MIT Sloan Management Review, April } \\
\text { 4, 2017, https://sloanreview.mit.edu. The general } \\
\text { background of this concept of maturity is based on L. } \\
\text { Hyatt, B. Hyatt, \& J. Hyatt, "Effective Leadership } \\
\text { Through Emotional Maturity," Academic Leadership } \\
\text { Journal 5, no. 2 (summer 2007): article 4. }\end{array}$ \\
\hline 4 & $\begin{array}{l}\text { The term "digital maturity" is closely related to digital } \\
\text { transformation. We can say that digital maturity is the } \\
\text { final stage of digital transformation, which companies } \\
\text { aspire to achieve, those companies that have achieved } \\
\text { such digital maturity, have now witnessed important } \\
\text { improvements in the operation of the company, and } \\
\text { have also increased customer satisfaction. }\end{array}$ & $\begin{array}{l}\text { Has your company achieved digital maturity? } \\
\text { by Alberto Dominguez | Dec 25, } 2017\end{array}$ \\
\hline
\end{tabular}


Therefore, we can conduct the synthesis of digital maturity definition according to different authors viewpoints. The synthesized definition of digital maturity is an adequate reaction of a company on changes in the digital sphere, implementation of digital achievements into business processes, as well as the development of staff's digital competences. However, this definition is quite wideranging. Due to the novelty of the term, there is no single, generally accepted definition characterizing the phenomenon of digital maturity. The purpose of this study is to develop a definition of digital maturity, which contains the basic elements, and to develop a methodology for assessing digital maturity. One should understand that digital transformation isn't the same as digital maturity. Digital maturity is the basement of digital transformation. Companies, aspiring to increase their level of digital maturity, go through digital transformation in all aspects of their activity.

Digital maturity is a gradual process of integration and implementation of organization processes, human, and other resources into digital processes and vice versa. In the process of reaching the maximum level of digital maturity, the organization must rely on a digitalization strategy with KPIs that allow them to evaluate implementation. If the organization does not have a digitalization strategy, this entails risks associated with the adoption of ineffective decisions that negatively affect the organization. Another prerequisite for achieving the highest level of digital maturity is the availability of the necessary infrastructure and relevant structures and units. They can provide the process of digital transformation in the organization. An important component of the highest level of digital maturity is the human factor, which includes the willingness of management and staff, as well as the necessary skills and competencies to digitalize the organization. Thus, maximizing the above aspects is the process of achieving digital maturity.

\section{METHOD}

As part of the study, a comparative analysis of digital maturity models, including Russian and foreign ones, was conducted. The following are brief characteristics, advantages and disadvantages of each of them.

1. ODM3 - open digital manufacturing maturity model of the Moscow School of Management Skolkovo. It is a maturity diagnostic survey for a digital manufacturing company. Survey list contains three segments: design and technological preparation of production, production, management, and logistics. Each section consists of segments that specify and disclose them in detail.

Advantages of the model:

1. Simplicity of application.

2. Developed in and for Russian realities and economic.

3 . It's available in open sources.

4. Detailed diagnostics (for large-scale companies).

Disadvantages of the model:

1. Diagnosis takes a long time.

2. The model does not apply to small-scale companies.
3. Detailed diagnostics (not all segments apply to each organization).

4. Difficulty in interpreting the results - there are no characteristics for each level of digital maturity.

2. Digital Maturity Matrix MIT \& Capgemini (Westermann, Bonnet, \& McAfee, 2014). It has a form of a matrix, on the $\mathrm{X}$-axis - Transformation management intensity, on the Y-axis - Digital intensity. Four types of digital maturity of the organization are identified, according to the results of the assessment: "beginners" - a low level of digitalization and management is not ready for changes, "fashionistas" - business digitalization is at a high level, but management is not transformed to meet the needs, "conservatives" - management is at a high level of readiness for changes, but the level of digitalization is low, "digirati" - a high level of digitalization, management fully meets the needs of the business that arose in the process of digital transformation.

Advantages of the model:

1. Simplicity of application.

2. Speed of diagnosis.

3. Based on expert evaluation and opinion.

4. Clear results (characteristics for the obtained results are available).

Disadvantages of the model:

1. Expert evaluation (cannot apply if there is insufficient information).

2. There is no complete information on the evaluation, only general characteristics and results of the work are presented.

3. Digital Maturity Model Universität St. Gallen (Back \& Berghaus, 2016). It is a model that has nine components, each of which is evaluated based on a survey, with a total of 64 indicators.

1. Customer experience.

2. Product innovation.

3. Strategy.

4. Organization.

5. Digitalization process.

6. Collaboration.

7. Information technology.

8. Culture and expertise.

9. Transformation management.

Advantages of the model:

1. Covers all major aspects of the organization.

2. Ease of use.

3. The methodology is publicly available.

4. Conducted based on a survey.

5. Suitable for primary, self-diagnosis within the organization.

Disadvantages of the model:

1. The model itself is presented only as a diagram of the organization's block aspects, but it does not provide a graphical representation of the level of digital maturity.

2. The result of the survey does not represent a specific numerical value that indicates a certain level of digital maturity.

3. Not suitable for a full assessment of the digital maturity level. 
4. TM Forum Digital Maturity Model. The model includes the following components:

1. Customer.

2. Strategy.

3. Technology.

4. Operations.

5. Organizational culture and people.

In total, all 5 segments include 28 sections +175 special criteria that fit the needs of specific, private organizations. Advantages of the model:

1. Using this model, you can conduct a deep, as detailed as possible analysis of the level of digitalization and digital maturity of the company.

2. It has a mobile app.

Disadvantages of the model:

1. The model is not publicly available in full size.

2. The app is not available in the Russian Google Play, Appstore.

3. TM Forum works on the foreign market and conducts research, therefore, this model cannot be applied in Russia. 5. The Open Digital Maturity Model (ODMM). It is an assessment tool that compares organization's current level of digital maturity with its own digital transformation goals and the performance of the best organizations in its segment.

It is a pie chart with a huge number of segments. The main ones are:

1. Strategic dynamism.

2. Customer centricity.

3. Digital culture, talent \& skills.
4. Innovation \& lean delivery.

5. Big data and AI.

6. Technology leadership.

Advantages of the model:

1. Adaptability to the individual needs of the organization.

2. Colorful graphical representation of the model.

3 . Broad coverage of aspects of the organization.

4. It considers modern digitalization paradigm trends such as Big data, AI, digital culture, etc.

5. Maximum depth assessment of digital maturity.

Disadvantages of the model:

1. There is no access to the full methodology.

2. It is oriented to foreign markets, so it is not represented on the Russian market.

3. Inapplicability in the Russian market (see point 2).

4. The evaluation takes quite a long time due to the many criteria for evaluation.

5. Despite its adaptability to individual requests, it is still more focused on companies in the digital \& IT field, rather than production, service, etc.

\section{RESULTS}

According to the analysis of digital maturity models, the authors' method for assessing the level of digital maturity of the organization was developed, based on the main definitions of digital maturity (Table 2) and three scales (Figure 1).

Table 2 Main definitions for digital maturity characteristics

\begin{tabular}{|l|l|}
\hline \multicolumn{1}{|c|}{ Element } & \multicolumn{1}{c|}{ Definition } \\
\hline Strategy & $\begin{array}{l}\text { The presence of a digital transformation strategy for the organization, its integration into the } \\
\text { development strategy of the organization. A list of specific, clear actions needed to achieve a high } \\
\text { level of digital maturity. At the same time, the digital transformation strategy should not "turn } \\
\text { upside down" the existing strategy in the organization, but organically build-in and enrich it, } \\
\text { bringing the necessary changes, technologies, and resources for the development and improvement } \\
\text { of the organization's performance indicators. }\end{array}$ \\
\hline Organization & $\begin{array}{l}\text { The most important component of achieving a high level of digital maturity is the readiness of the } \\
\text { management for changes in the organizational culture, restructuring of business processes, and } \\
\text { improving their management skills }\end{array}$ \\
\hline People & $\begin{array}{l}\text { Successful implementation of the strategy implies the readiness of the staff and their awareness of } \\
\text { upcoming changes. Engagement, motivation, and participation of people in strategic changes } \\
\text { within an organization is the key to success. }\end{array}$ \\
\hline Technologies & $\begin{array}{l}\text { Technologies are the main driver of digital transformation. A high level of digital maturity implies } \\
\text { a high level of digital competence for employees involved in the digital transformation process. }\end{array}$ \\
\hline Data & $\begin{array}{l}\text { Proper usage and management of data is the basis of digitalization, which includes the } \\
\text { harmonization of data creation and generation, as well as other related processes. Increasing data } \\
\text { volumes and their quality require organizations to focus. Properly managed, consistent and reliable } \\
\text { dagitalization. }\end{array}$ \\
\hline
\end{tabular}


is difficult for them to make changes in business processes, management may not be aimed at managing a modern organization, staff may not have the necessary skills to work with modern technologies, the technical equipment of the organization may also not allow digitalization of the business.

"Catching-ups" - organizations of this type are only going to develop a strategy for digital transformation, they are aware of its need, but do not have it. Management is visionary, they are aware of the need for change and are ready for it, as well as employees. The company either has the necessary technical equipment or is ready to purchase it.

"Off-track" - have a digitalization strategy, but have difficulty implementing it. Management wants to change the organization to meet the demands of the times. On the path to successful digitalization are problems associated with human resources, mathematical and technical supply, digitization of data, etc.

"Leaders" - have a digitalization strategy and implement it. Usually, these are modern organizations that have a business model that has been modernized and adapted to the age of digitalization. The management has a leadership type of thinking that leads the organization to success. The organization has the necessary technical base, employees have the necessary skills and competencies to work with it. The developed method includes a questionnaire consisting of three blocks of questions, each of which contains 10 questions. The score is assigned according to the digital maturity levels that were previously presented in the article. The result of the evaluation is to collect empirical data and test the methodology for researchers, and clear graphical representation of the current situation in the organization, as well as recommendations by the available results for the business.

At the moment, two organizations were evaluated using the developed methodology - the manufacture of oil and gas equipment company and the clothing factory. Each assessment provided a level of digital maturity, a graphical representation of the results obtained and recommendations.

The organization that produces oil and gas equipment is engaged in the production of equipment for oil production, tools for rope work and well repair, valves, primary converters, sensors, complex systems, etc. Figure 2 shows the summary result of the organization by the level of digital maturity. 


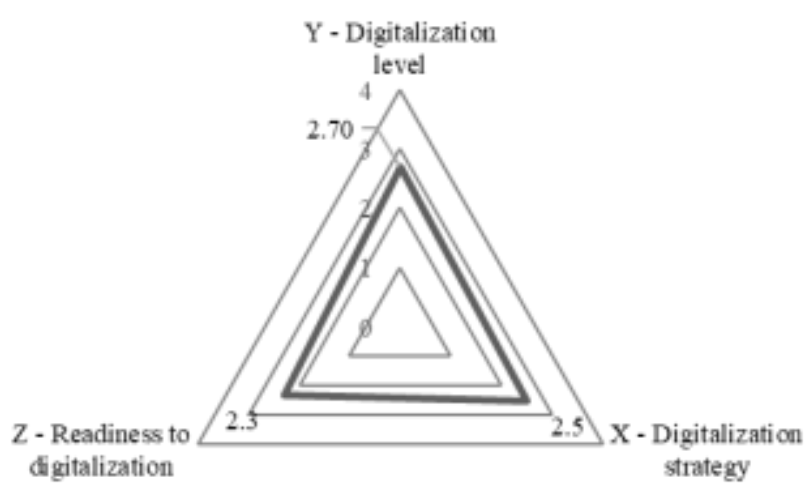

Figure 2 Summary of the resulting digital maturity level for an oil and gas equipment manufacturing organization

The frequency analysis shown in figure 3 is used as an additional tool for determining the level of digital maturity. Based on the frequency analysis, we can conclude that the company producing oil and gas equipment belongs to the "Off-tracks", but because the assessment is carried out not only based on the numerical values obtained but also taking into account the specific characteristics of each organization, in this case, the organization is at the "Catching-ups" level, since they do not have a strategy for digitalizing the organization.

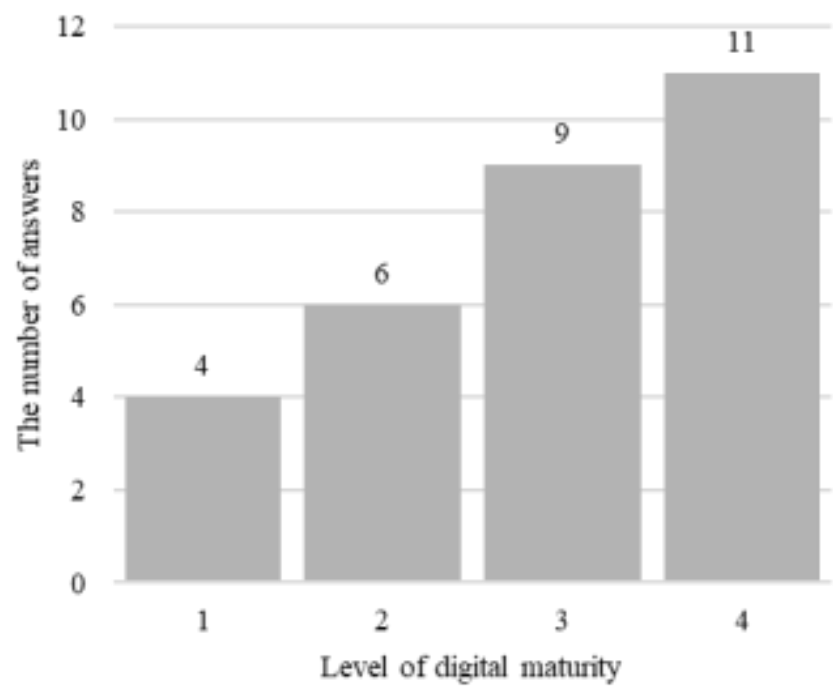

Figure 3 Frequency analysis for an organization that produces oil and gas equipment

Furthermore, the final values for each scale were analysed (figure 1) to determine the areas where the organization is performing well and the growth areas for which recommendations were developed.

Figure 4 shows the totals for the first organization, followed by general recommendations.

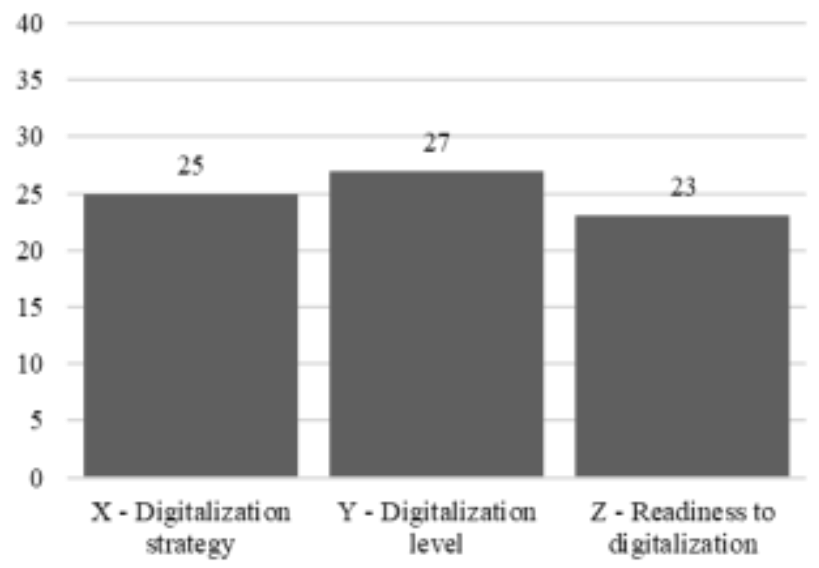

Figure 4 Totals for three scales for an organization that produces oil and gas equipment

Based on the assessment, the level of digital maturity of "Catching-ups" was determined for the organization that produces oil and gas equipment and the following recommendations were developed:

- Implementation of VR technologies, digital counterparts to reduce the cost of errors at the design stage.

- Development of KPIs for evaluating the implementation of the digitalization strategy.

- Organize the process of knowledge transfer in the organization.

- Develop a digitalization strategy to increase the level of digital maturity of the organization.

Next, we will consider the results obtained when evaluating the clothing factory. The clothing factory belongs to the Russian enterprises of the clothing industry specializing in the production of outerwear for men and women, school clothes for boys and girls. The head office and main production facilities located in Novosibirsk. Figure 5 shows a summary of the assessment of the level of digital maturity of a clothing factory.

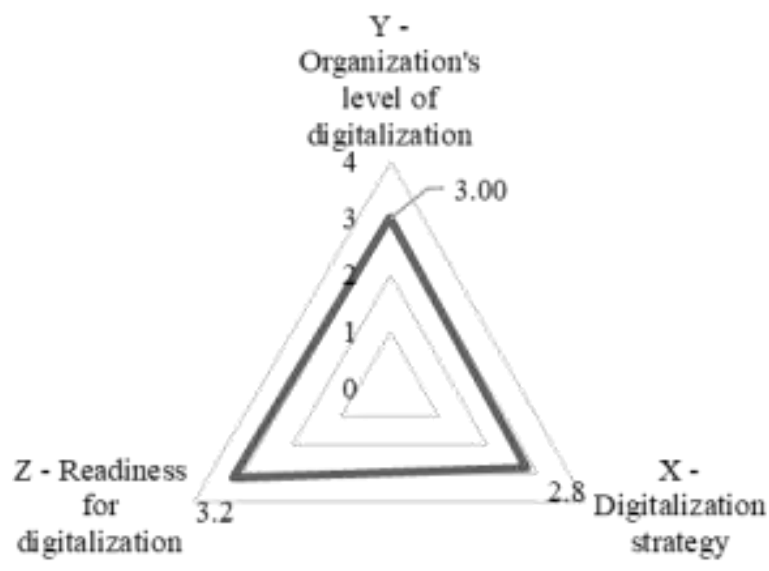

Figure 5 Summary results of the assessment of the level of digital maturity of a clothing factory 
Figure 6 shows a frequency analysis that clearly shows that the clothing factory has a high level of digital maturity. however, since the assessment is based not only on numerical indications but also on the characteristics of each organization, the clothing factory is assigned a digital maturity level - "Off-track", since the organization has not developed KPIs that can be used to evaluate the implementation of the digitalization strategy.

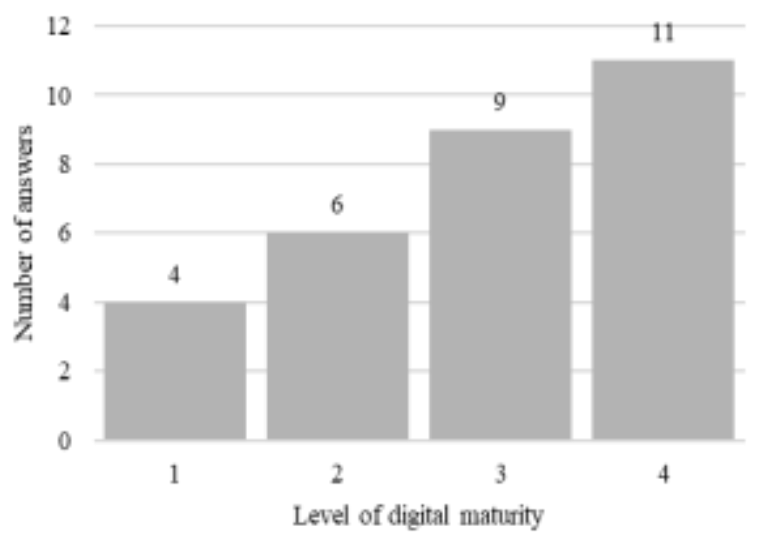

Figure 6 Frequency analysis for a clothing factory

To develop recommendations and identify the strengths of the organization, an analysis of the final values was conducted (figure 7).

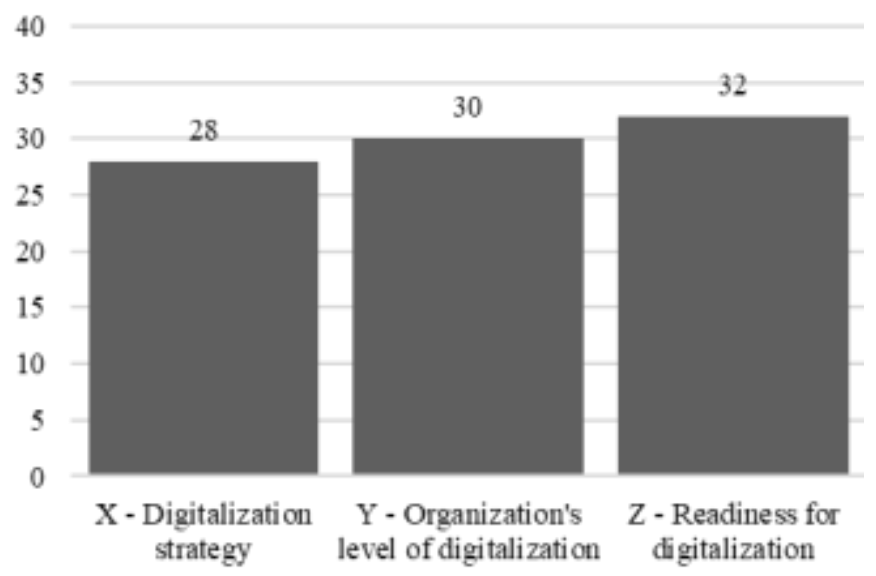

Figure 7 Totals for three scales for a clothing factory

Based on the assessment of the level of digital maturity, it was concluded that the clothing factory belongs to the group of "Off-track". Implementation of the developed recommendations will strengthen the factory's position and raise it to the next level of digital maturity. The recommendations are the following:

- Develop the KPIs for evaluating the implementation of the digitalization strategy.

- Appoint internal experts responsible for the implementation of the digitalization strategy.

\section{DISCUSSION}

The developed methodology requires further testing in order to verify its universality and applicability to various fields. The purpose of the development of this methodology was to create a simple, understandable, transparent tool for use in various fields since when working with a similar Russian methodology and analyzing foreign ones, obvious shortcomings were identified, such as: incomplete initial data for analysis, the complexity of the assessment (large time costs ), the lack of a universal approach and focus on specific areas and/or sizes of organizations. Another objective is the ability to visualize the results of the study.

Further testing of the methodology will make it possible to establish whether it can be applied in other areas (services, education, medicine, hotel business, KMPG companies, etc.). This methodology allows using data mining methods to plan future actions of the organization to increase productivity and improve the digitalization process in order to become a leader in its field.

\section{REFERENCES}

[1] George Westerman, Didier Bonnet, and Andrew McAfee "The Nine Elements of Digital Transformation" MIT Sloan Management Review January 07, 2014

[2] G.C. Kane, "Digital Maturity, Not Digital Transformation," MIT Sloan Management Review, April 4, 2017, https://sloanreview.mit.edu. The general background of this concept of maturity is based on L. Hyatt, B. Hyatt, \& J. Hyatt, "Effective Leadership Through Emotional Maturity," Academic Leadership Journal 5, no. 2 (summer 2007): article 4.

[3] A. Dominguez Has your company achieved digital maturity? [Electronic resource] // December 25, 2017. URL: https://ehorus.com/digital-maturity/

[4] D. Field, S. Patel, H. Leon The Dividends of Digital Marketing Maturity [Electronic resource] // Boston Consulting Group, February 18, 2019. - URL: https://www.bcg.com/ru-

ru/publications/2019/dividends-digital-marketingmaturity.aspx

[5] Digital economic: textbook / V.D. Markova. - M.: INFRA-M, 2018 .- 186 p. - (Higher Education: Undergraduate) (in Russian)

[6] Order of the Government of the Russian Federation on approval of the program "Digital Economy of the Russian Federation" [Electronic resource]: July 16, 
maturity and managerial competences: A model and its preliminary assessment, in: Lecture Notes in Information Systems and Organisation, vol. 33, 2020, p. 261-272, 15th Conference of the Italian chapter of Association for Information Systems, AIS 2018; Pavia; Italy. DOI: 10.1007/978-3-030-23665-6_19

[17] Schumacher, A., Erol, S., \& Sihn, W., A maturity model for assessing industry 4.0 readiness and maturity of manufacturing enterprises, in: Procedia CIRP, vol. 52, 2016, p. 161-166. DOI: https://doi.org/10.1016/j.procir.2016.07.040

[18] Kidschun, F., Hecklau, F., Orth, R., Wackernagel, J.P., Singer, K., Development of an organizational structure model as a basis for the assessment of the digital transformation of organizations, in: Proceedings of the 15th European Conference on Management, Leadership and Governance, ECMLG 2019-2020, p. 217-226, 15th European Conference on Management, Leadership and Governance, ECMLG 2019; Porto; Portugal. DOI: 10.34190/MLG.19.107

[19] Zangiacomi, A., Pessot, E., Fornasiero, R., Bertetti, M., Sacco, M., Moving towards digitalization: a multiple case study in manufacturing, in: Production Planning and Control, vol. 31, Issue 2-3, 17 February $2020, \quad$ p. $143-157 . \quad$ DOI: 10.1080/09537287.2019.1631468

[20] Schallmo, D., Williams, C.A., Lohse, J., Digital strategy - Integrated approach and generic options, in: International Journal of Innovation Management, vol. 23, Issue 8, 1 December 2019, DOI: 10.1142/S136391961940005X

[21] Rader, D., Digital maturity - the new competitive goal, in: Strategy and Leadership, vol. 47, Issue 5, 16 September 2019, Pages 28-35. DOI: 10.1108/SL-062019-0084

[22] Gustafsson, E., Jonsson, P., Holmström, J., Digital product fitting in retail supply chains: maturity levels and potential outcomes, in: Supply Chain Management, vol. 24, Issue 5, 19 August 2019, Pages 574-589. DOI: 10.1108/SCM-07-2018-0247

[23] Vial, G., Understanding digital transformation: A review and a research agenda, in: Journal of Strategic Information Systems, vol. 28, Issue 2, June 2019, Pages 118-144. DOI: 10.1016/j.jsis.2019.01.003 services/our-insights/a-roadmap-for-a-digitaltransformation

[16] Ravarini, A.aEmail Author, Locoro, A.aEmail Author, Martinez, M., Digital transformation projects 